ARTICLE

\title{
The role of allyl ammonium salts in palladium- catalyzed cascade reactions towards the synthesis of spiro-fused heterocycles
}

Fei $Y e^{1,2,3}$, Yao Ge $e^{2,3}$, Anke Spannenberg ${ }^{2}$, Helfried Neumann (i) ${ }^{2} \&$ Matthias Beller (i] ${ }^{2 凶}$

There is a continuous need for designing new and improved synthetic methods aiming at minimizing reaction steps while increasing molecular complexity. In this respect, catalytic, one-pot cascade methodologies constitute an ideal tool for the construction of complex molecules with high chemo-, regio-, and stereoselectivity. Herein, we describe two general and efficient cascade procedures for the synthesis of spiro-fused heterocylces. This transformation combines selective nucleophilic substitution $\left(S_{N} 2^{\prime}\right)$, palladium-catalyzed Heck and $\mathrm{C}-\mathrm{H}$ activation reactions in a cascade manner. The use of allylic ammonium salts and specific Pd catalysts are key to the success of the transformations. The synthetic utility of these methodologies is showcased by the preparation of 48 spiro-fused dihydrobenzofuranes and indolines including a variety of fluorinated derivatives.

\footnotetext{
${ }^{1}$ Key Laboratory of Organosilicon Chemistry and Material Technology of Ministry of Education, and Key Laboratory of Organosilicon Material Technology of Zhejiang Province, Hangzhou Normal University, No. 2318, Yuhangtang Road, 311121 Hangzhou, PR China. ${ }^{2}$ Leibniz-Institute for Catalysis, Albert-Einstein-Str. 29a, 18059 Rostock, Germany. ${ }^{3}$ These authors contributed equally: Fei Ye, Yao Ge. ${ }^{{ }^{\circledR}}$ email: matthias.beller@catalysis.de
} 
T he development of novel chemical transformations increasing molecular complexity enables significant innovation potential in life and material sciences. In this respect, catalytic cascade or domino processes offer strong impetus for new methodology developments ${ }^{1-3}$. Compared to traditional consecutive procedures, they permit several practical advantages: In addition to improved step-economy, waste generation from multiple iterations of reaction, workup, and purification procedures are minimized. Consequently, diverse and complex organic molecules can be assembled not only in a faster, but also more sustainable way.

Since their discovery in the 1970 s and $80 \mathrm{~s}^{4-8}$, palladiumcatalyzed $\mathrm{C}-\mathrm{C}$ bond forming reactions have become the most popular homogeneous catalytic processes in organic chemistry and industrial fine chemical synthesis ${ }^{9-12}$. Their ability to form (stereo)selectively carbon-carbon bonds under mild conditions made them "a true power tool for organic synthesis"13. Specifically, the intramolecular Heck reaction provides an entry to useful palladium complexes with quaternary carbon centers as intermediates (Fig. 1b, I-2), which can be further valorized to a multitude of valuable building blocks ${ }^{14-18}$. Notably, the combination of this reaction with $\mathrm{C}-\mathrm{H}$ activation processes has also been studied, giving access to structurally unique spiro compounds ${ }^{19-31}$, which possess interesting biological activities (Fig. 1c) ${ }^{32-38}$. However, the necessity of pre-synthesized starting materials in the existing methods limits the full exploitation of this elegant concept and is often tedious. In our quest for the development of new cascade methodologies, we had the idea to provide a more facile entry to this class of compounds by combining three (or four) palladium-catalyzed coupling processes, namely Tsuji-Trost and Heck reactions followed by selective $\mathrm{C}-\mathrm{H}$ activation (and alkyne insertion) to assemble complex organic molecules from easily available substrates (Fig. 1).

Herein, we describe our recent efforts to establish a palladiumcatalyzed allylic substitution/Heck/C-H activation(/alkyne) cascade processes for the synthesis of spiro-fused heterocycles. Key challenges of such processes are obviously the compatibility of the well-matched reactant partners ${ }^{39}$, the required conditions of the individual reactions, the development of a general catalyst system able to promote all three (or four) transformations efficiently, and to achieve the needed high chemo-selectivity, regio-selectivity, and stereoselectivity throughout all elementary steps.

\section{Results}

Reaction development. Recently, Lautens, Schoenebeck and coworkers reported the synthesis of spiro-fused heterocycles through an intramolecular Heck/C-H activation sequence using specific alkene-tethered aryl iodides (Fig. 1a) ${ }^{40-42}$. Regarding the starting materials, those substrates might be preferably prepared through an initial palladium-catalyzed Tsuji-Trost allylation of 2halophenols, which would provide a more efficient and stepeconomic way ${ }^{43-45}$. Following this initial idea, we investigated the coupling of 2-iodophenol (1a) with 2-phenylallyl acetate (2a) in the presence of $\mathrm{PdBr}_{2} / \mathbf{L 1}$ (Fig. 2a) and various other palladium catalysts (for details see Supplementary Information, Supplementary Table 1). Unfortunately, in no case the desired spiro-

a

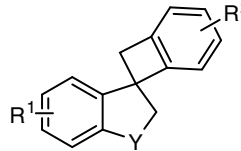

16 examples $54-90 \%$ yields

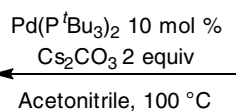

Acetonitrile, $100^{\circ} \mathrm{C}$

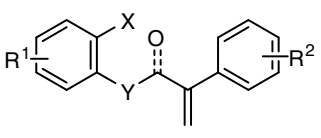

$(\mathrm{Y}=\mathrm{O}$ or $\mathrm{NR})$

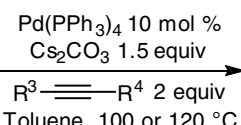

Toluene, 100 or $120^{\circ} \mathrm{C}$

b

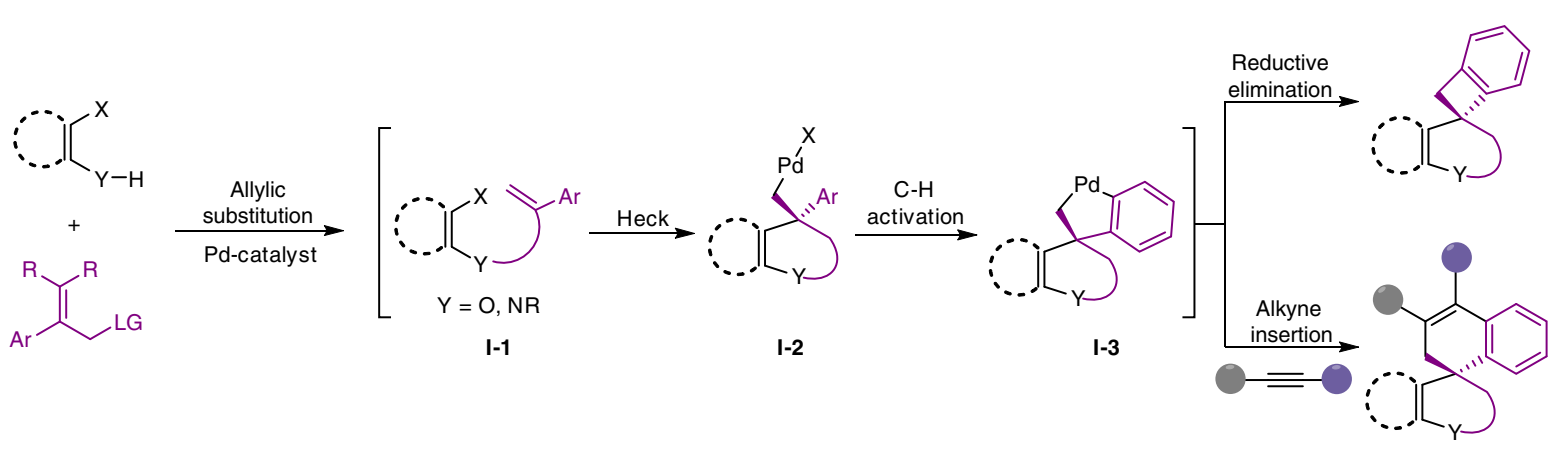

C

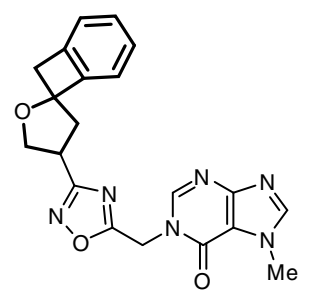

TRP cation channel antagonists

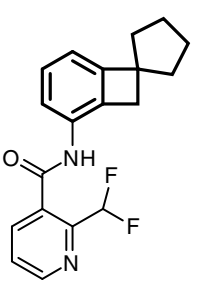

Antimicrobial agent

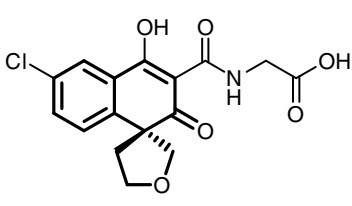

Prolyl hydroxylase inhibitory activity

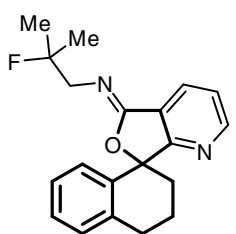

Herbicide $53-94 \%$ yields $>20: 1 \mathrm{rr}$

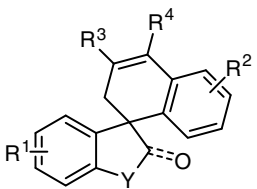

$$
1 \text { examples }
$$$$
1 \mathrm{rr}
$$

Fig. 1 Concepts. a Previous work: palladium-catalyzed intramolecular cyclization for the synthesis of spiroheterocycles. b This work: palladium-catalyzed allylic substitution/Heck/C-H activation(/alkyne) cascade processes. c Selected examples of related bio-active spiro compounds. 


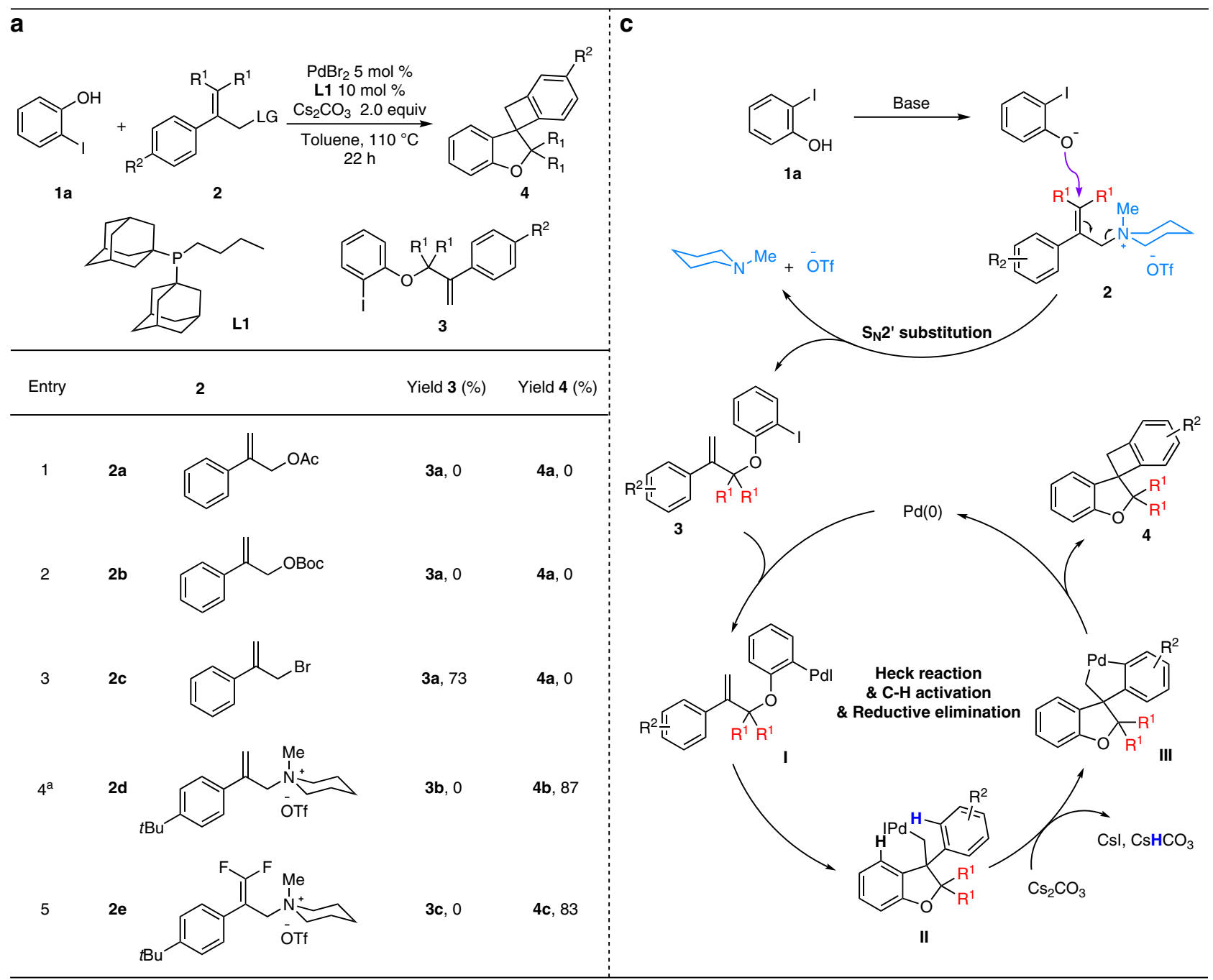

b

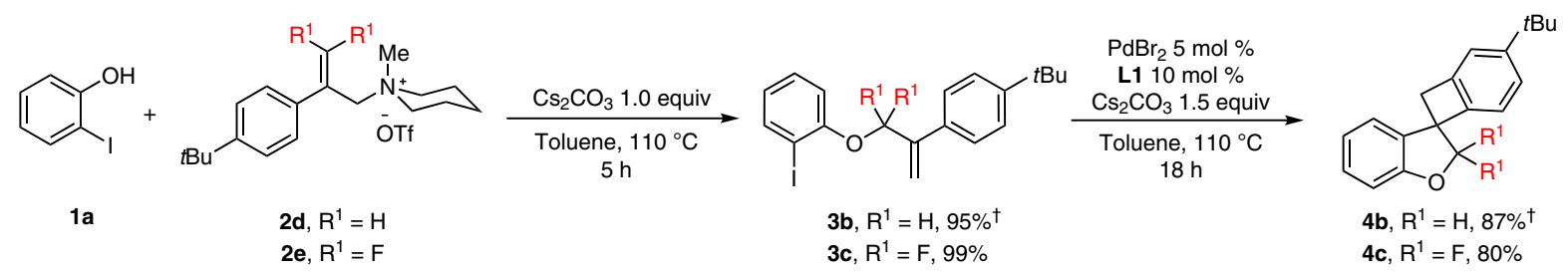

†The reaction was performed at $90^{\circ} \mathrm{C}$.

Fig. 2 Constructing molecular complexity: spiro-fused heterocycles from simple starting materials. a Preliminary results show the importance of ammonium salts as the partners of the nucleophile. $\mathbf{b}$ Control experiments shown that the allylic aryl ether $\mathbf{3}$ was formed in situ as important intermediate during the cascade procedure. $\mathrm{c} \mathrm{A} \mathrm{S}_{\mathrm{N}} 2^{\prime}$ substitution process was proposed for the first reaction step, followed by sequence palladium-catalyzed Heck reaction/C-H activation/Pd reductive elimination to provide the target product 4.

fused product $4 \mathbf{a}$ was observed and no conversion took place. Similar results were obtained when the tert-butyl (2-phenylallyl) carbonate (2b) was used instead of $\mathbf{2 a}$. When more reactive 2phenylallyl bromide $\mathbf{2 c}$ was introduced, only the alkene-tethered aryl iodide $\mathbf{3 a}$ was isolated in $73 \%$ yield instead of product $\mathbf{4 a}$. To improve the reactivity of the starting material further on, other allylic leaving groups were considered. In this respect, allylic ammonium salts, which have been largely neglected in intermolecular palladium-catalyzed allylic substitutions, attracted our attention $39,46,47$. This class of compounds are in general highly stable and can be conveniently prepared from a variety of amines. Surprisingly, testing 2d in the presence of the $\mathrm{PdBr}_{2} / \mathbf{L} \mathbf{1}$ catalyst, the desired cascade process took place and product $\mathbf{4 b}$ was obtained in $87 \%$ isolated yield! This means that each individual step proceeds with an efficiency of at least $95 \%$. At this point, it should be mentioned that allylic ammonium salts are also known to undergo direct $\mathrm{S}_{\mathrm{N}} 2$-substitution or $\mathrm{S}_{\mathrm{N}} 2$-substitution reactions under basic conditions ${ }^{48-50}$. To understand whether the first reaction step is really palladium-catalyzed, $\mathbf{2 d}$ was treated with $\mathbf{1 a}$ in the presence of 1 equiv. of base. Interestingly, the allyl aryl ether $\mathbf{3 b}$ was obtained in high yield (95\%). Subsequent reaction in the presence of our regular palladium catalyst led to full consumption of $\mathbf{3 b}$, providing the desired spiro-benzocyclobutane $\mathbf{4 b}$ in $87 \%$ yield (Fig. 2b). Obviously, applying substrate $2 \mathbf{d}$ does not allow to distinguish between $\mathrm{S}_{\mathrm{N}} 2$-mechanism and $\mathrm{S}_{\mathrm{N}} 2$ '-mechanism in the first reaction step due to its symmetry. Based on the 
actual interest in fluorinated building blocks ${ }^{51-53}$, the gemdifluorinated allylic ammonium salt $2 \mathbf{e}^{39}$ was reacted with 2iodophenol, which gave product $3 c$ in $99 \%$ yield and excellent regioselectivity. Again, the following palladium-catalyzed steps took place smoothly and provided $4 \mathrm{c}$ in high yield (80\%). Similarly, the direct conversion of $2 \mathrm{e}$ proceeded efficiently to give $4 \mathrm{c}$ in $83 \%$ isolated yield (Fig. 2a, entry 5). It should be noted that related fluorinated heterocycles in general cannot be easily prepared $^{54}$ and that to the best of our knowledge no example of such spiro compounds has been reported yet. Apart from $\mathbf{2 e}$, other related ammonium salts $\mathbf{2} \mathbf{f}-\mathbf{2} \mathbf{i}$ underwent similar coupling processes to provide the desired product $4 \mathrm{c}$ in slight lower yield (62-75\%) (for details see Supplementary Information, Supplementary Table 2).

To obtain optimal results, an extensive evaluation of the reaction conditions of the model systems was performed (for details see Supplementary Information, Supplementary Tables 19) and revealed three significant points: (1) The catalyst system is crucial in this cascade process and only in the presence of sterically hindered and electron-rich diadamantyl phosphines such as L1, the desired product was obtained in high yield. (2) $\mathrm{Cs}_{2} \mathrm{CO}_{3}$ and toluene were independently identified as the most effective base and solvent, which nearly doubled the product yield compared to other common bases and solvents. (3) In addition, the concentrations of substrates are decisive. Using an equimolar amount of both substrates led to the best result while an excess of either ammonium salt or aryl halide considerably decreased the yield of 4 . Based on all these observations, a plausible mechanism for the formation of benzocyclobutane derivative $\mathbf{4}$ is proposed in Fig. 2c: Initially, 2-iodophenol $\mathbf{1}$ and ammonium salt $\mathbf{2}$ underwent a base mediated $\mathrm{S}_{\mathrm{N}} 2$ ' allylic substitution in a highly regioselective manner. To further confirm the $\mathrm{S}_{\mathrm{N}} 2$ ' route, deuterium substituted ammonium salt was tested, details see Supplementary Information, Supplementary Fig. 1. Next, intramolecular palladiumcatalyzed Heck reaction of the in situ generated compound 3 followed by site-selective $\mathrm{C}-\mathrm{H}$ activation forms the spiropalladacycle III. Final reductive elimination regenerates the palladium species and produces the desired product ${ }^{40}$. Noteworthily, this novel cascade reaction is a rare example of a domino process involving $\mathrm{S}_{\mathrm{N}} 2^{\prime}$ substitution with subsequent metal-catalyzed transformations ${ }^{55,56}$.

Scope for the formation of spiro-fused benzocyclobutene derivatives. With the optimized reaction conditions in hand, the general feasibility of this approach was examined. As shown in Fig. 3, allylic ammonium salts with different substituents in 3position including $\mathrm{H}, \mathrm{F}, \mathrm{CF}_{3}$, directly afforded $\mathbf{4 b}-\mathbf{4 e}$ in all cases in good to high isolated yields. For disubstituted substrate $\mathbf{2 j}$ with $-\mathrm{F}$ and $-\mathrm{CF}_{3}$ substituents in 3-position, high diastereoselectivity for two adjacent quaternary carbon centers was obtained (4e, $71 \%)$. Next, the reaction of gem-difluorinated allylic ammonium salts $\mathbf{2 k - 2 u}$ with aryl halides 1a-1o (for details see Supplementary Information, Supplementary Fig. 2) was investigated. Most of the ammonium salts were conveniently obtained from commercially available phenylboronic acid and vinyl bromides via Suzuki reaction, base-mediated amination, and final $N$-methylation ${ }^{39}$. With regard to the cascade reaction, both electron-donating groups including alkyl, aryl, alkoxy and aryloxy and electronwithdrawing groups including fluoro and chloro were perfectly compatible with the conditions, and the corresponding products $\mathbf{4 f}-\mathbf{4 l}$ were obtained in $53-86 \%$ yield. The molecular structure of these highly strained 5,4-spirocycles was unambiguously confirmed by X-ray crystal structure analysis of 4 f. Both diphenylamino-substituted and trimethylsilyl-substituted spiro compounds $\mathbf{4 m}$ and $\mathbf{4 n}$ were successfully formed in high yield.
Furthermore, dibenzofuran-derived ammonium salt underwent the cascade process, leading to the construction of the heterocycle-embedded tetracyclic framework 40 in $60 \%$ yield. Gratifyingly, the more complex derivative $4 \mathbf{p}$ containing two spiro-fused benzocyclobutanes was smoothly generated in $51 \%$ yield via a consecutive two-fold cascade process using the corresponding bis-ammonium salt as the reagent.

Next, we explored the scope of our methodology with respect to the aryl halide coupling partner. In addition to 2 -iodophenols 1a-11, 2-bromophenol 1m, 2-chlorophenol 1n, and 2-iodoaniline 10 were also investigated. The latter case highlights the possibility to construct 3-spiro-indolines, specifically 2 -fluorinated indolines (4ad and 4ae), which are of interest as natural products and pharmaceutical molecules ${ }^{57,58}$. As depicted in Fig. 3, several different aryl halides gave the expected tetracyclic products under the standard conditions. Interestingly, considering the three-step cascade, these transformations proceeded in good to excellent yields with either electron-rich or electron-deficient substituents. Notably, substrates containing heteroarenes, such as the quinoline derivative $\mathbf{1 k}$, provided the $N, O$-fused heterocycle $\mathbf{4 a b}$ in $60 \%$ yield. Moreover, the $L$-tyrosine derived product 4 ac was obtained by a concise cascade transformation $(\mathrm{dr}=1: 1)$.

Three-component spirocyclization reaction. Considering the versatility of the in-situ-generated palladacycles III ${ }^{16,26,27}$, subsequent functionalization including carbene and alkyne insertion should allow for the efficient construction of other classes of novel spiro compounds $29,30,41,42$. To demonstrate this synthetic potential, we performed the reaction of $\mathbf{1 a}$ and $\mathbf{2 e}$ with two equiv. of an additional unsymmetrical alkyne 5a (ethyl 3-phenyl-propynoate). Indeed, the envisioned cascade process combining $\mathrm{S}_{\mathrm{N}} 2$ ' substitution, palladium-catalyzed Heck/C-H activation and final alkyne insertion provided in a straightforward manner only one regioisomer of the respective 6,5-spirocycles 6 (regioselectivity: $>20: 1)$. Under standard conditions, the desired product $6 \mathbf{a}$ was obtained in $73 \%$ yield; however, in this case the highly reactive palladacycle III also underwent minor reductive elimination and the 5,4-spirocycle 4c was detected in $14 \%$ yield. Pleasantly, increasing substrate concentration in the presence of the extended ligand $\mathbf{L 3}$ provided exclusively $\mathbf{6 a}$ in high yield (85\% isolated yield; for a brief evaluation of reaction conditions see Supplementary Information, Supplementary Table 10).

The generality of this second three-component cascade procedure is shown by variation of five aryl iodides, nine ammonium salts and six alkynes (Fig. 4). In all cases, the domino reaction proceeded smoothly with valuable substituents and functional groups, including alkoxy, aryloxy, halide, silyl, and amino, giving the corresponding products $\mathbf{6 a}-\mathbf{6} \mathbf{h}$ in good to high yields with excellent regioselectivities. The molecular structure of 6a was confirmed by X-ray crystallography. Substituents on the phenyl ring of aryl iodide displayed only a minor influence on the reactivity and provided $\mathbf{6 i}-\mathbf{6} \mathbf{k}$ in high yields. Notably, various unsymmetrical alkynes with different substituents on the triple bond afforded 61-6q with excellent degrees of both chemoselectivities and regioselectivities. For example, internal alkynes bearing $-\mathrm{COPh},-\mathrm{COCH}_{3}$, and $-\mathrm{CO}_{2} \mathrm{Me}$ substituents gave the corresponding products 61-6n in 79\%, 45 and 79\% isolated yield, respectively. It is worthy to note that 3-phenyl-2-propynenitrile and 1,3-diynes were compatible in this transformation, affording 6o-6q in $40-94 \%$ isolated yield. Finally, the construction of 3spiro-indoline $6 \mathbf{r}$ was also achieved in $54 \%$ yield.

\section{Discussion}

In summary, we have developed two efficient cascade processes involving allylic substitution (via $\mathrm{S}_{\mathrm{N}} 2$ '-mechanism), palladium- 


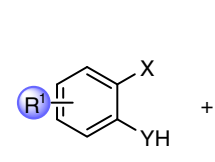

1

$(\mathrm{X}=\mathrm{I}, \mathrm{Br}, \mathrm{Cl} ; \mathrm{Y}=\mathrm{O}, \mathrm{NTs})$

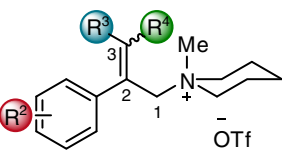

2

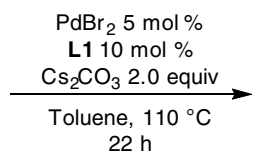

$22 \mathrm{~h}$

\section{a: Scope of ammonium salts}<smiles>CC(C)(C)c1ccc2c(c1)CC21COc2ccccc21</smiles>

4b, $87 \%^{\dagger}$

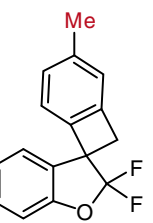

4g, $53 \%$

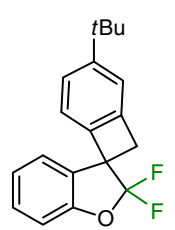

4c, $X=1,83 \%$
$X=B r, 60 \%$ $\mathrm{X}=\mathrm{Cl}, 58 \%$

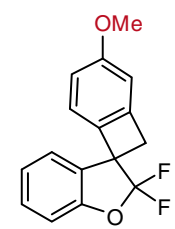

$4 h, 78 \%$<smiles>CC(C)(C)c1ccc2c(c1)CC21COc2cc(-c3ccccc3)ccc21</smiles>

$4 d, 62 \%^{\dagger}$<smiles>FC1(F)Oc2ccccc2C12Cc1cc(Oc3ccccc3)ccc12</smiles>

$4 \mathbf{i}, 71 \% \dagger$

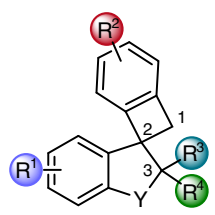

4b-4z, 4aa-4ae

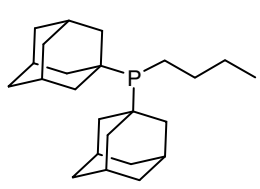

L1<smiles>CC(C)(C)c1ccc2c(c1)CC21c2ccccc2OC1(F)C(F)(F)F</smiles>

$4 e, 71 \%{ }^{\dagger}(d r>20 / 1)$

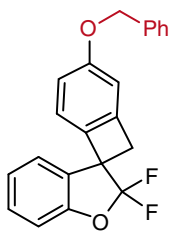

4j, $86 \%$

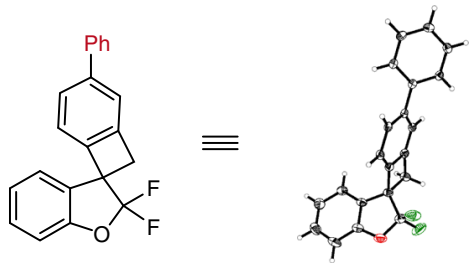

4f, $78 \%$

\section{(30\% probability level)}

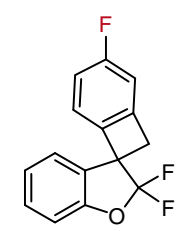

4k, $76 \%$<smiles>FC1(F)Oc2ccccc2C12Cc1cc(Cl)ccc12</smiles>

4I, $72 \%$<smiles>[NH3+][N+](=O)c1ccc(C2(c3ccccc3)Oc3ccccc32)cc1</smiles>

$4 \mathrm{~m}, 78 \%$<smiles>Cc1ccc(C2(C(F)(F)F)Oc3ccccc3C2c2ccccc2)cc1</smiles>

4n, $80 \%$<smiles>COc1ccccc1C1(C(F)(F)F)Oc2cccc3c1cccc23</smiles>

4o, $60 \%$ ‡

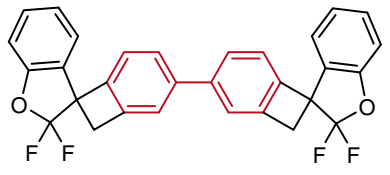

$4 p, 51 \%$ §ा $(d r>20 / 1)$

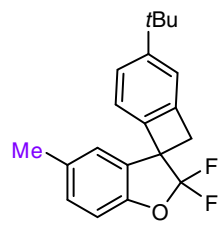

$4 q, 86 \%$<smiles>CCc1ccc2c(c1)C1(c3ccc(Br)cc3)CC2C(F)(F)O1</smiles>

$4 r, 68 \%$<smiles>FC1(F)Oc2ccc(Br)cc2C1(Cc1ccccc1)c1ccc(Br)cc1</smiles>

4s, $62 \%$<smiles>FC1(F)Oc2ccc(-c3ccccc3)cc2C1(Cc1ccccc1)c1ccc(Br)cc1</smiles>

4t, $76 \%$<smiles></smiles>

$4 u, 61 \% \S$<smiles>CC(C)(C)c1ccc2c(c1)CC21c2cc(Cl)ccc2OC1(F)F</smiles>

4v, $74 \%{ }^{\#}$<smiles></smiles>

$4 w, 82 \%$<smiles>CC1(c2ccc([Tl])cc2)c2cccc(F)c2OC1(F)F</smiles>

$4 x, R^{2}=t B u, 69 \%$ $4 y, R^{2}=T M S, 72 \%$<smiles></smiles>

4z, $\mathrm{R}^{2}=t \mathrm{Bu}, 75 \%$

4aa $R^{2}=O B n, 69 \%$<smiles>CC(C)(C)c1ccc2c(c1)CC21c2cc(Cl)c3cccnc3c2OC1(F)F</smiles>

4ab, $60 \% \S$<smiles>COC(=O)c1ccccc1NC(Cc1ccc2c(c1)CC(F)(F)OC2(F)F)C(=O)NC(=O)c1ccccc1</smiles>

4ac , $46 \% \S(d r=1: 1)$<smiles>CN1c2ccccc2CC1(F)c1ccc(I)cc1</smiles>

4ad, $\mathrm{R}^{2}=t \mathrm{Bu}, 50 \% \S$ 4ae, $R^{2}=C l, 58 \%$

Fig. 3 Palladium-catalyzed cascade reaction of ammonium salts with aryl halides. Standard reaction conditions: $1(0.2 \mathrm{mmol}), 2(0.2 \mathrm{mmol}), \mathrm{Cs}_{2} \mathrm{CO}_{3}$ $(0.4 \mathrm{mmol}), \mathrm{PdBr}_{2}(0.01 \mathrm{mmol}), \mathbf{L 1}(0.02 \mathrm{mmol})$, toluene $(2.5 \mathrm{~mL})$, the reaction mixture was performed at $110^{\circ} \mathrm{C}$ under argon atmosphere for $22 \mathrm{~h}$, isolated

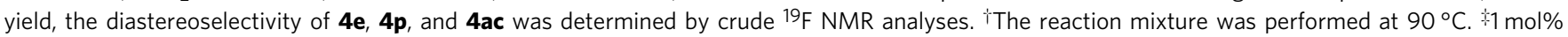
$\mathrm{PdBr}_{2}$ and 2 mol\% $\mathbf{L 1}$ were used. ${ }^{\S} 10$ mol\% $\mathrm{PdBr}_{2}$ and 20 mol\% $\mathbf{L 1}$ were used. ${ }^{\top} \mathbf{1}(0.2 \mathrm{mmol}), \mathbf{2}(0.1 \mathrm{mmol})$ were used. ${ }^{\#} 2 \mathrm{~mol} \% \mathrm{PdBr}_{2}$ and $4 \mathrm{~mol} \% \mathbf{L 1}$ were used. 


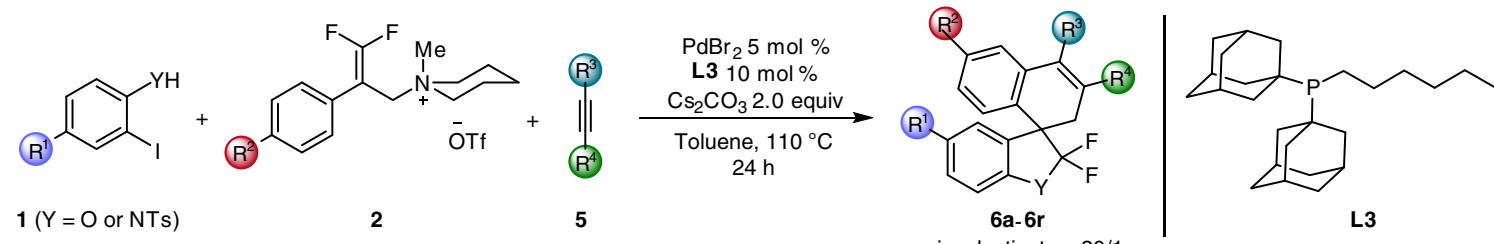

regioselectivety $>20 / 1$<smiles>C#CCOC1=C(c2ccccc2)c2cc(C(C)(C)C)ccc2C2(C1)c1ccccc1OC2(F)F</smiles>

$6 a, 85 \%$<smiles>CCOC(=O)C1=C(c2ccccc2)c2cc(OC)ccc2C2(C1)c1ccccc1OC2(F)F</smiles>

$6 e, 78 \%$<smiles>CCOC(=O)C1=C(c2ccccc2)c2cc(C(C)(C)C)ccc2C2(C1)c1ccc(F)cc1OC2(F)F</smiles>

$6 \mathbf{j}, 81 \%$

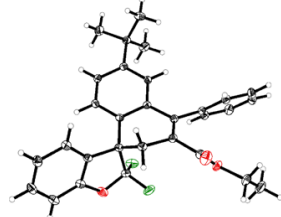

Displacement ellipsoid plot of $6 \mathbf{a}$ (30\% probability level)<smiles>CCOC(=O)C1=C(c2ccccc2)c2cc(S(C)(C)C)ccc2C2(C1)c1ccccc1OC2(F)F</smiles>

$6 f, 82 \%$<smiles>CCOC(=O)C1=C(c2ccccc2)c2cc(C(C)(C)C)ccc2C2(C1)c1cc(C)ccc1OC2(F)F</smiles>

6k, $82 \%$<smiles>CCOC(=O)C1=C(c2ccccc2)c2cc(C)ccc2C2(C1)c1ccccc1OC2(F)F</smiles>

6b, $70 \%$<smiles>CCOC(C1=C(c2ccccc2)c2cc(N)ccc2C2(C1)c1ccccc1OC2(F)F)c1ccccc1</smiles>

6g, $80 \%$

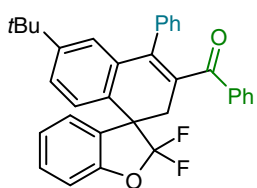

6I, $79 \%$<smiles>CCOC(=O)C1=C(c2ccccc2)c2cc(-c3ccccc3)ccc2C2(C1)c1ccccc1OC2(F)F</smiles>

$6 c, 70 \%$<smiles>CCOC(=O)C(OCC)C1=C(c2ccccc2)c2cc(F)ccc2C2(C1)c1ccccc1OC2(F)F</smiles>

$6 h, 53 \%$<smiles>CC(=O)C1=C(c2ccccc2)c2cc(C(C)(C)C)ccc2C2(C1)c1ccccc1OC2(F)F</smiles>

$6 \mathrm{~m}, 45 \%$<smiles>CCOC(=O)C1=C(c2ccccc2)c2cc(Oc3ccccc3)ccc2C2(C1)c1ccccc1OC2(F)F</smiles>

6d, $66 \%{ }^{\dagger}$<smiles>CCOC(=O)C1=C(c2ccccc2)c2cc(C(C)(C)C)ccc2C2(C1)c1cc(-c3ccccc3)ccc1OC2(F)F</smiles>

6i, $80 \%$

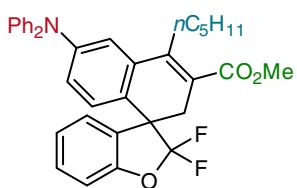

6n, $79 \%$<smiles>FC1(F)Oc2ccccc2C12CC(C#Cc1ccccc1)=C(c1ccccc1)c1ccccc12</smiles>

6o, $45 \%$ ‡

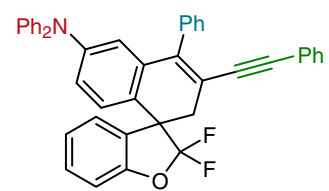

$6 p, 40 \%$ ‡<smiles>N#CC1=C(c2ccccc2)C2(CC(F)(F)Oc3ccccc32)c2ccc(Br)cc21</smiles>

6q, $94 \%^{\ddagger}$<smiles>[Y5]N1c2ccccc2C2(CC(C#N)=C(c3ccccc3)c3cc(Cl)ccc32)C1(F)F</smiles>

$6 r, 54 \%$

Fig. 4 Palladium-catalyzed three-component cascade spriocyclizations. Standard reaction conditions: $1(0.2 \mathrm{mmol}), 2(0.2 \mathrm{mmol}), 5(0.4 \mathrm{mmol}), \mathrm{Cs}_{2} \mathrm{CO}_{3}$ $(0.4 \mathrm{mmol}), \mathrm{PdBr}_{2}(0.01 \mathrm{mmol}), \mathbf{L} 3(0.02 \mathrm{mmol})$, toluene $(1.0 \mathrm{~mL})$, the reaction mixture was stirred at $110^{\circ} \mathrm{C}$ under argon atmosphere for $24 \mathrm{~h}$, isolated yield, the regioselectivity of $\mathbf{6}$ was determined by crude ${ }^{19} \mathrm{~F} \mathrm{NMR}$ analyses. ${ }^{\dagger} 2 \mathrm{~mol} \% \mathrm{PdBr}_{2}$ and $4 \mathrm{~mol} \% \mathbf{L} \mathbf{3}$ were used. $\$ 10 \mathrm{~mol} \% \mathrm{PdBr}_{2}$ and 20 mol\% $\mathbf{L} \mathbf{3}$ were used.

catalyzed Heck, remote $\mathrm{C}-\mathrm{H}$ activation, and reductive elimination or alkyne insertion for the straightforward synthesis of 5,4spiroheterocycles and 6,5-spiroheterocycles in good to high yields with excellent selectivities. Crucial for the success of these transformations is the use of specifically activated allylic substrates (ammonium salts) in combination with special $\mathrm{PdBr}_{2} /$ AlkylPAd $_{2}$ catalytic systems. Under optimal conditions diverse (fluorinated) spiro-dihydrobenzofurans and spiro-indolines are achieved in an unprecedented fast and step-economic way, without need for purification of intermediates. We believe these methodologies demonstrate the potential of catalytic cascade processes for a straightforward increase of molecular complexity of simple and easily available aryl halides.

\section{Methods}

General procedure for the preparation of spiro-fused benzocyclobutanes 4 .

To a $25 \mathrm{ml}$ oven-dried pressure tube equipped with a magnetic stir bar were added 2-halophenol or aniline $\mathbf{1}(0.2 \mathrm{mmol})$, ammonium salt $\mathbf{2}(0.2 \mathrm{mmol}), \mathrm{Cs}_{2} \mathrm{CO}_{3}(130$ $\mathrm{mg}, 0.4 \mathrm{mmol}), \mathrm{PdBr}_{2}(2.7 \mathrm{mg}, 0.01 \mathrm{mmol}), \mathbf{L 1}(7.2 \mathrm{mg}, 0.02 \mathrm{mmol})$, and then degassed toluene $(2.5 \mathrm{~mL})$ was introduced under argon atmosphere. The sealed pressure tube was heated and stirred at $110^{\circ} \mathrm{C}$ for $22 \mathrm{~h}$. The reaction mixture was allowed cooling to room temperature, diluted with ethyl acetate $(10 \mathrm{ml})$, and filtered through a short pad of celite eluting with ethyl acetate $(3 \times 10 \mathrm{ml})$. After evaporation, the residue was purified by chromatography on basic aluminum oxide (It is worthy to note that the 2-fluorinated product can only be separated without decomposition using basic aluminum oxide) to afford the desired product 4 .

General procedure for the preparation of spiro-fused dihydronaphthalenes 6 To a $25 \mathrm{ml}$ oven-dried pressure tube equipped with a magnetic stir bar were added 2-halophenol or aniline $\mathbf{1}(0.2 \mathrm{mmol})$, ammonium salt $\mathbf{2}(0.2 \mathrm{mmol})$, alkyne $\mathbf{5}$ $(0.4 \mathrm{mmol}), \mathrm{Cs}_{2} \mathrm{CO}_{3}(130 \mathrm{mg}, 0.4 \mathrm{mmol}), \mathrm{PdBr}_{2}(2.7 \mathrm{mg}, 0.01 \mathrm{mmol}), \mathbf{L} 3(7.7 \mathrm{mg}$, $0.02 \mathrm{mmol})$, and then degassed toluene $(1 \mathrm{ml})$ was introduced under argon atmosphere. The sealed pressure tube was heated and stirred at $110^{\circ} \mathrm{C}$ for $24 \mathrm{~h}$. The reaction mixture was allowed cooling to room temperature, diluted with ethyl acetate $(10 \mathrm{ml})$, and filtered through a short pad of celite eluting with ethyl acetate $(3 \times 10 \mathrm{ml})$. After evaporation, the residue was purified by chromatography on basic aluminum oxide (It is worthy to note that the 2 -fluorinated product can only be separated without decomposition using basic aluminum oxide) to afford the desired product 6 . 


\section{Data availability}

The authors declare that all the data supporting this study, including the experimental details, data analysis, and spectra for all unknow compounds, see Supplementary Files. All data underlying the findings of this work are available from the corresponding author upon reasonable request. The X-ray crystallographic coordinates for structures reported in this study have been deposited at the Cambridge Crystallographic Data Centre (CCDC), under deposition numbers 2006609 (4f) and 2006610 (6a). These data are provided free of charge by the joint Cambridge Crystallographic Data Centre and Fachinformationszentrum Karlsruhe Access Structures service www.ccdc.cam.ac.uk/ structures.

Received: 30 June 2020; Accepted: 22 September 2020; Published online: 23 October 2020

\section{References}

1. Wasilke, J., Obrey, S. J., Baker, R. T. \& Bazan, G. C. Concurrent tandem catalysis. Chem. Rev. 105, 1001-1020 (2005).

2. Fogg, D. E. \& Dos Santos, E. N. Tandem catalysis: a taxonomy and illustrative review. Coord. Chem. Rev. 248, 2365-2379 (2004).

3. Parsons, P. J., Penkett, C. S. \& Shell, A. J. Tandem reactions in organic synthesis: novel strategies for natural product elaboration and the development of new synthetic methodology. Chem. Rev. 96, 195-206 (1996).

4. Heck, R. F. Palladium-catalyzed reactions of organic halides with olefins. Acc. Chem. Res. 12, 146-151 (1979).

5. Negishi, E. Palladium- or nickel-catalyzed cross coupling. A new selective method for carbon-carbon bond formation. Acc. Chem. Res. 15, 340-348 (1982).

6. Stille, J. K. The palladium-catalyzed cross-coupling reactions of organotin reagents with organic electrophiles. Angew. Chem. Int. Ed. 25, 508-524 (1986).

7. Miyaura, N. \& Suzuki, A. Palladium-catalyzed cross-coupling reactions of organoboron compounds. Chem. Rev. 95, 2457-2483 (1995).

8. Trost, B. M. New rules of selectivity: allylic alkylations catalyzed by palladium. Acc. Chem. Res. 13, 385-393 (1995).

9. Wu, X. F., Neumann, H. \& Beller, M. Palladium-catalyzed carbonylative coupling reactions between $\mathrm{Ar}-\mathrm{X}$ and carbon nucleophiles. Chem. Soc. Rev. 40, 4986-5009 (2011).

10. Biffis, A., Centomo, P., Del Zotto, A. \& Zecca, M. Pd metal catalysts for crosscouplings and related reactions in the 21st century: a critical review. Chem. Rev. 118, 2249-2295 (2018).

11. Brennführer, A., Neumann, H. \& Beller, M. Palladium-catalyzed carbonylation reactions of aryl halides and related compounds. Angew. Chem. Int. Ed. 48, 4114-4133 (2009).

12. Johansson Seechurn, C. C., Kitching, M. O., Colacot, T. J. \& Snieckus, V. Palladium-catalyzed cross-coupling: a historical contextual perspective to the 2010 Nobel Prize. Angew. Chem. Int. Ed. 51, 5062-5085 (2012).

13. Nicolaou, K. C. \& Sorensen, E. J. Classics in Total Synthesis. (VCH: Weinheim, 1996) 566.

14. Jones, D. J., Lautens, M. \& Mcglacken, G. P. The emergence of Pd-mediated reversible oxidative addition in cross coupling, carbohalogenation and carbonylation reactions. Nat. Catal. 2, 843-851 (2019).

15. Nicolaou, K. C., Bulger, P. G. \& Sarlah, D. Palladium-catalyzed cross-coupling reactions in total synthesis. Angew. Chem. Int. Ed. 44, 4442-4489 (2005).

16. Ping, Y., Li, Y., Zhu, J. \& Kong, W. Construction of quaternary stereocenters by palladium-catalyzed carbopalladation-initiated cascade reactions. Angew. Chem. Int. Ed. 58, 1562-1573 (2019).

17. Shibasaki, M., Vogl, E. M. \& Ohshima, T. Asymmetric heck reaction. Adv. Synth. Catal. 346, 1533-1552 (2004)

18. Yang, X., Kalita, S. J., Maheshuni, S. \& Huang, Y.-Y. Recent advances on transition-metal-catalyzed asymmetric tandem reactions with organoboron reagents. Coord. Chem. Rev. 392, 35-48 (2019).

19. Grigg, R., Meerholtz, P. F. C. \& Sridharan, V. Palladium catalysed synthesis of spiroindolines. Tetrahedron 50, 359-370 (1994).

20. Piou, T., Neuville, L. \& Zhu, J. Spirocyclization by palladium-catalyzed domino heck-direct $\mathrm{C}-\mathrm{H}$ arylation reactions: synthesis of spirodihydroquinolin-2-ones. Org. Lett. 14, 3760-3763 (2012).

21. Liu, J. G., Chen, W. W., Gu, C. X., Xu, B. \& Xu, M. H. Access to spiroindolines and spirodihydrobenzofurans via Pd-catalyzed domino Heck spiroyclization through C-H activation and carbene insertion. Org. Lett. 20, 2728-2732 (2018).

22. Piou, T., Neuville, L. \& Zhu, J. Activation of a C(sp3)-H bond by a transient sigma-alkylpalladium(II) complex: synthesis of spirooxindoles through a palladium-catalyzed domino carbopalladation/C(sp3)-C(sp3) bond-forming process. Angew. Chem. Int. Ed. 51, 11561-11565 (2012).
23. Ruck, R. T. et al. Palladium-catalyzed tandem Heck reaction/C-H functionalization-preparation of spiro-indane-oxindoles. Angew. Chem. Int. Ed. 47, 4711-4714 (2008)

24. Satyanarayana, G., Maichle-Mossmer, C. \& Maier, M. E. Formation of pentacyclic structures by a domino sequence on cyclic enamides. Chem. Commun. 1571-1573 (2009).

25. Shao, C., Wu, Z., Ji, X., Zhou, B. \& Zhang, Y. An approach to spirooxindoles via palladium-catalyzed remote $\mathrm{C}-\mathrm{H}$ activation and dual alkylation with $\mathrm{CH}_{2} \mathrm{Br}_{2}$. Chem. Commun. 53, 10429-10432 (2017).

26. Franzoni, I., Yoon, H., Garcia-Lopez, J. A., Poblador-Bahamonde, A. I. \& Lautens, M. Exploring the mechanism of the Pd-catalyzed spirocyclization reaction: a combined DFT and experimental study. Chem. Sci. 9, 1496-1509 (2018).

27. Pérez-Gómez, M. et al. Synthesis and reactivity of model intermediates proposed for the $\mathrm{Pd}$-catalyzed remote $\mathrm{C}-\mathrm{H}$ functionalization of $\mathrm{N}$-(2-haloaryl) acrylamides. Organometallics 36, 4465-4476 (2017).

28. Sickert, M., Weinstabl, H., Peters, B., Hou, X. \& Lautens, M. Intermolecular domino reaction of two aryl iodides involving two $\mathrm{C}-\mathrm{H}$ functionalizations. Angew. Chem. Int. Ed. 53, 5147-5151 (2014).

29. Pérez-Gómez, M. \& García-López, J. A. Trapping sigma-alkyl-palladium(II) intermediates with arynes encompassing intramolecular $\mathrm{C}-\mathrm{H}$ activation: spirobiaryls through Pd-catalyzed cascade reactions. Angew. Chem. Int. Ed. 55, 14389-14393 (2016)

30. Pérez-Gómez, M., Hernandez-Ponte, S., Bautista, D. \& García-López, J. A. Synthesis of spiro-oxoindoles through Pd-catalyzed remote $\mathrm{C}-\mathrm{H}$ alkylation using alpha-diazocarbonyl compounds. Chem. Commun. 53, 2842-2845 (2017).

31. Ye, J. \& Lautens, M. Palladium-catalysed norbornene-mediated $\mathrm{C}-\mathrm{H}$ functionalization of arenes. Nat. Chem. 7, 863-870 (2015).

32. Carreira, E. M. \& Fessard, T. C. Four-membered ring-containing spirocycles: synthetic strategies and opportunities. Chem. Rev. 114, 8257-8322 (2014).

33. Trost, B. \& Brennan, M. Asymmetric syntheses of oxindole and indole spirocyclic alkaloid natural products. Synthesis 2009, 3003-3025 (2009).

34. Terrett, J. A. et al. Oxadiazole transient receptor potential channel inhibitors. US20190284179A1 (2019).

35. Bubost, C. et al. Benzocyclobutane carboxamides. WO2015063086A1 (2015)

36. Allen, J. et al. Naphthalenone compounds exhibiting prolyl hydroxylase inhibitory activity, composition, and uses thereof. WO2008076427A2 (2008)

37. Waespe, H.-R., Van Lommen, G. R. E. \& Sipido, V. K. Isonicotinic acid derivatives and related spiro compounds with herbicidal action. WO1992009577A1 (1992)

38. Shirai, F. et al. Discovery of novel spiroindoline derivatives as selective tankyrase inhibitors. J. Med. Chem. 62, 3407-3427 (2019).

39. Tang, L., Liu, Z. Y., She, W. \& Feng, C. Selective single C-F bond arylation of trifluoromethylalkene derivatives. Chem. Sci. 10, 8701-8705 (2019).

40. Ye, J. et al. Remote C-H alkylation and C-C bond cleavage enabled by an in situ generated palladacycle. Nat. Chem. 9, 361-368 (2017).

41. Yoon, H., Lossouarn, A., Landau, F. \& Lautens, M. Pd-Catalyzed spirocyclization via $\mathrm{C}-\mathrm{H}$ activation and benzyne insertion. Org. Lett. 18, 6324-6327 (2016)

42. Yoon, H., Rolz, M., Landau, F. \& Lautens, M. Palladium-catalyzed spirocyclization through $\mathrm{C}-\mathrm{H}$ activation and regioselective alkyne insertion. Angew. Chem. Int. Ed. 56, 10920-10923 (2017).

43. Trost, B. M. \& Crawley, M. L. Asymmetric transition-metal-catalyzed allylic alkylations: applications in total synthesis. Chem. Rev. 103, 2921-2943 (2003)

44. Butt, N. A. \& Zhang, W. Transition metal-catalyzed allylic substitution reactions with unactivated allylic substrates. Chem. Soc. Rev. 44, 7929-7967 (2015).

45. Trost, B. M. Metal catalyzed allylic alkylation: its development in the trost laboratories. Tetrahedron 71, 5708-5733 (2015).

46. Soheili, A. \& Tambar, U. K. Tandem catalytic allylic amination and $[2,3]$ Stevens rearrangement of tertiary amines. J. Am. Chem. Soc. 133, 12956-12959 (2011)

47. West, T. H., Daniels, D. S., Slawin, A. M. \& Smith, A. D. An isothioureacatalyzed asymmetric [2,3]-rearrangement of allylic ammonium ylides. J. Am. Chem. Soc. 136, 4476-4479 (2014).

48. Arfaoui, A., Saâdi, F., Nefzi, A. \& Amri, H. Easy conversion of dimethyla(bromomethyl)fumarate into functionalized allyl ethers mediated by DABCO. Synth. Commun. 45, 2627-2635 (2015).

49. Baidya, M., Remennikov, G. Y., Mayer, P. \& Mayr, H. SN2' versus SN2 reactivity: control of regioselectivity in conversions of Baylis-Hillman adducts. Chem. Eur. J. 16, 1365-1371 (2010)

50. Kulchat, S. \& Lehn, J. M. Dynamic covalent chemistry of nucleophilic substitution component exchange of quaternary ammonium salts. Chem. Asian J. 10, 2484-2496 (2015).

51. Hu, X. G. \& Hunter, L. Stereoselectively fluorinated N-heterocycles: a brief survey. Beilstein J. Org. Chem. 9, 2696-2708 (2013). 
52. Wang, J. et al. Fluorine in pharmaceutical industry: fluorine-containing drugs introduced to the market in the last decade (2001-2011). Chem. Rev. 114, 2432-2506 (2014).

53. Guo, P., Zhang, R., Wang, X., Wang, Z. \& Ding, K. Synthesis of chiral tertiary alpha,alpha-difluoromethyl carbinols by $\mathrm{Cu}$-catalyzed asymmetric propargylation. Chem. Eur. J. 25, 16425-16434 (2019).

54. Fujita, T., Sugiyama, K., Sanada, S., Ichitsuka, T. \& Ichikawa, J. Platform for ring-fluorinated benzoheterole derivatives: palladium-catalyzed regioselective 1,1-difluoroallylation and heck cyclization. Org. Lett. 18, 248-251 (2016).

55. Sharma, U. K., Sharma, N., Vachhani, D. D. \& Van Der Eycken, E. V. Metalmediated post-Ugi transformations for the construction of diverse heterocyclic scaffolds. Chem. Soc. Rev. 44, 1836-1860 (2015).

56. Zhang, Z. et al. Tandem SN2' nucleophilic substitution/oxidative radical cyclization of aryl substituted allylic alcohols with 1,3-dicarbonyl compounds. Org. Biomol. Chem. 15, 3239-3247 (2017).

57. Zheng, C. \& You, S. L. Exploring the chemistry of spiroindolenines by mechanistically-driven reaction development: asymmetric pictet-spenglertype reactions and beyond. Acc. Chem. Res. 53, 974-987 (2020).

58. Cheng, D., Ishihara, Y., Tan, B. \& Barbas, C. F. Organocatalytic asymmetric assembly reactions: synthesis of spirooxindoles via organocascade strategies. ACS Catal. 4, 743-762 (2014).

\section{Acknowledgements}

We are grateful for financial support from the State of Mecklenburg-Western Pomerania and the Federal State of Germany (BMBF). We also thank the analytic department (LIKAT) for their kind support.

\section{Author contributions}

M.B. and F.Y. conceived and designed the experiments. F.Y. and Y.G. performed the experiments and analyzed the data. A.S. performed the X-ray analysis. H.N. participated in the discussions and supported the project. M.B. and F.Y. prepared the manuscript with feedback from all authors.

\section{Funding}

Open Access funding enabled and organized by Projekt DEAL.

\section{Competing interests}

The authors declare no competing interests.

\section{Additional information}

Supplementary information is available for this paper at https://doi.org/10.1038/s41467020-19110-3.

Correspondence and requests for materials should be addressed to M.B.

Peer review information Nature Communications thanks the anonymous reviewer(s) for their contribution to the peer review of this work.

Reprints and permission information is available at http://www.nature.com/reprints

Publisher's note Springer Nature remains neutral with regard to jurisdictional claims in published maps and institutional affiliations.

(c) (i)

Open Access This article is licensed under a Creative Commons Attribution 4.0 International License, which permits use, sharing, adaptation, distribution and reproduction in any medium or format, as long as you give appropriate credit to the original author(s) and the source, provide a link to the Creative Commons license, and indicate if changes were made. The images or other third party material in this article are included in the article's Creative Commons license, unless indicated otherwise in a credit line to the material. If material is not included in the article's Creative Commons license and your intended use is not permitted by statutory regulation or exceeds the permitted use, you will need to obtain permission directly from the copyright holder. To view a copy of this license, visit http://creativecommons.org/ licenses/by/4.0/.

(C) The Author(s) 2020 